\title{
Tuning the Bonding of a $\mu$-Mesityl Ligand on Dicopper(I) through a Proton-Responsive Expanded PNNP Pincer Ligand
}

\author{
Errikos Kounalis, Martin Lutz, and Daniël L. J. Broere*
}

Cite This: Organometallics 2020, 39, 585-592

Read Online

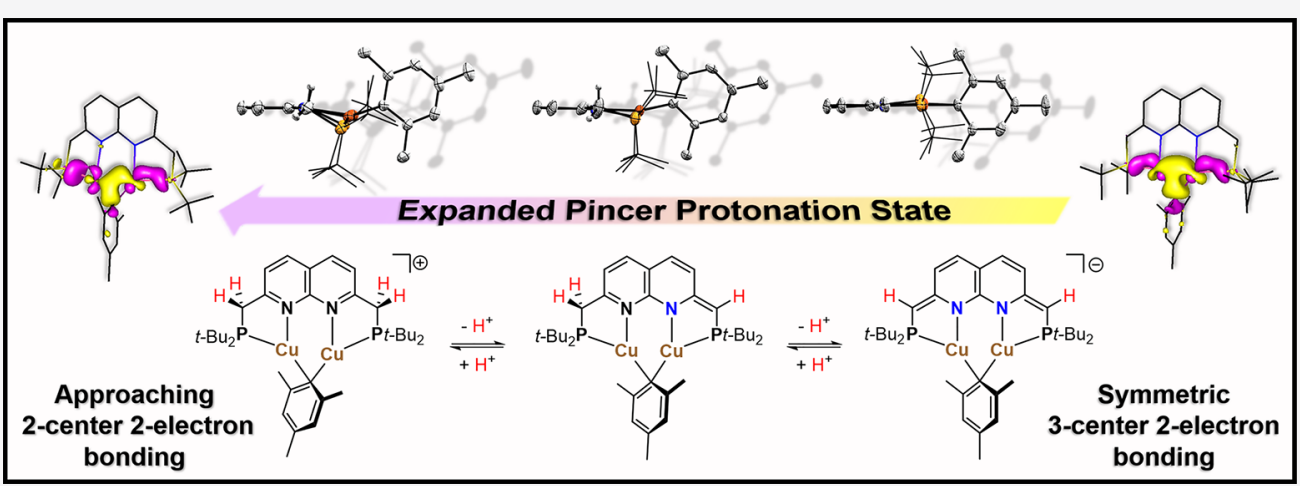

ABSTRACT: We report the synthesis and characterization of a series of cationic, neutral, and anionic dicopper(I) complexes featuring a $\mu$-mesityl ligand and a naphthyridine-derived PNNP expanded pincer ligand. Structural characterization showed that the protonation state of the dinucleating ligand has a pronounced effect on the bending and tilting of the $\mu$-mesityl ligand. DFT calculations indicate that the varying orientations of the $\mu$-mesityl ligand are inherent due to changes in electronic structure rather than crystal-packing effects. NBO analysis reveals how the interactions that contribute to the three-center-two-electron bond between the $\mu$-mesityl ligand and the dicopper core change for the various degrees of observed bending and tilting.

\section{INTRODUCTION}

Organocopper compounds play an important role in synthetic chemistry, where they enable a variety of reactions including conjugate addition, epoxide ring opening, substitution, and coupling reactions. ${ }^{1}$ The higher stability of arylcopper species in comparison to their alkyl counterparts has enabled isolation and detailed characterization of various arylcopper complexes. $^{1,2}$ A prime example is mesitylcopper, ${ }^{3}$ which exists as a mixture of tetrameric $[\mathrm{CuMes}]_{4}$ (major) and pentameric $[\mathrm{CuMes}]_{5}$ (minor) in solution. ${ }^{4}$ The relatively high kinetic stability and commercial availability of this organocopper compound has resulted in it becoming a powerful tool in synthetic chemistry. ${ }^{5}$

Arylcopper compounds typically form aggregates featuring $\mu$-aryl ligands that bring two copper atoms in close proximity (2.37-2.45 $\AA$ ) due to electron-deficient three-center-twoelectron (3c-2e) bonds. In the absence of bulky substituents or donor sites on the $\mu$-aryl ligand a symmetric binding mode is typically observed featuring equivalent copper sites. $^{2-4,6} \mathrm{~A}$ qualitative description of the bonding situation of such symmetrically bound $\mu$-aryl ligands is depicted in Scheme 1 (left). ${ }^{2,6}$ The main contributing molecular orbital (MO) involves donation from the filled $\mathrm{sp}^{2} \mathrm{C}_{\mathrm{ipso}}$ orbital into a combination of unfilled $4 \mathrm{~s}$ orbitals on the copper atoms (A). Additional donation from the $\mu$-aryl ligand in a higher-energy
Scheme 1. Qualitative Representation of the Molecular Orbitals Involved in Symmetric 3c-2e Bonding of Bridging Aryl Ligands to a Dicopper(I) Core (A), Other Minor Contributions (B and $C$ ), and the Unsymmetric 2c-2e Binding Mode Typically Observed in Arylcuprates (D) ${ }^{a}$

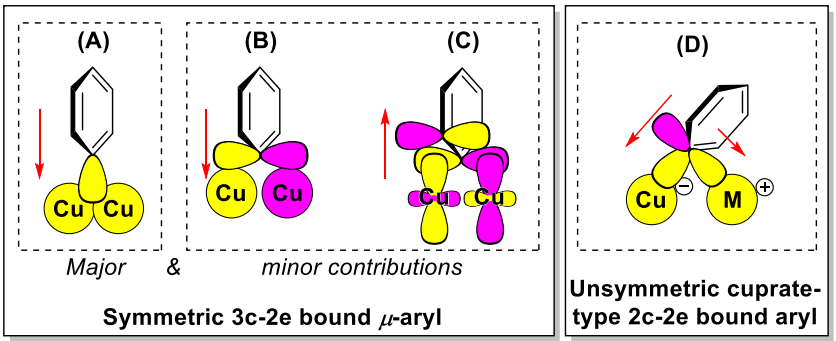

${ }^{a}$ The red arrow indicates the direction of electron donation.

MO involves donation from a filled $\pi$ orbital into an empty antibonding combination on the copper atoms (B). Finally,

Received: December 4, 2019

Published: February 4, 2020 
back-donation from a filled antibonding combination on the copper atoms into a $\pi^{*}$ orbital on the $\mu$-aryl ligand can play a role (C). The interaction types $\mathbf{B}$ and $\mathbf{C}$ are maximized when the $\mu$-aryl ligand plane is orthogonal to the dicopper vector. The presence of ortho substituents on the $\mu$-aryl ligand in this orientation prevents free rotation and increases the kinetic stability of the arylcopper complex. ${ }^{1,2}$ In contrast to the symmetric $3 \mathrm{c}-2 \mathrm{e}$ binding mode typically observed in neutral arylcopper compounds, arylcuprates typically display a strong two-center-two-electron (2c-2e) $\sigma$-bound aryl ligand featuring a weaker $\pi$-type interaction with a metal cation in close proximity (D, Scheme 1, right). ${ }^{7}$ Alternatively, sterically demanding substituted $\mu$-aryl ligands can also result in neutral arylcopper complexes featuring a $2 \mathrm{c}-2 \mathrm{e}$ binding mode without a stabilizing cation $\pi$-type interaction. ${ }^{8}$

We recently reported the proton-responsive "expanded

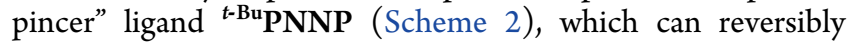

Scheme 2. Dinucleating "Expanded Pincer" Ligand

${ }^{t}$-Bu PNNP and the Partial and Full Dearomatization upon Single and Double Deprotonation, Respectively
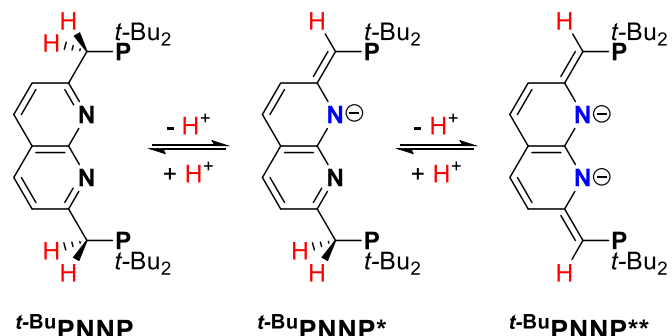

shuttle among three protonation states on dicopper(I) concomitant with partial $\left({ }^{t-B u}\right.$ PNNP*) or full $\left({ }^{t-B u}\right.$ PNNP**) dearomatization of the naphthyridine core. ${ }^{9}$ Inspired by recent work from the Tilley group on aryl group transfer reactions ${ }^{10}$ and the remarkable stabilization of $\mu$-alkyl complexes ${ }^{11}$ on a naphthyridine bis(dipyridyl) dicopper(I) core, we set out to explore how the various protonation states of ${ }^{t-B u}$ PNNP affect the bonding in $\mu$-aryl dicopper(I) compounds. Herein, we describe how a reaction between ${ }^{t-B u} \mathbf{P N N P}$ and mesitylcopper readily forms a discrete dinuclear form of $\mathrm{Cu}_{2} \mathrm{Mes}$. Both the anionic and cationic analogues were prepared by deprotonation or protonation of the complex, respectively, which takes place selectively on the expanded pincer ligand. The series of the three isolated $\mathrm{Cu}_{2} \mathrm{Mes}$ complexes affords key insights into the metric and spectroscopic features of the ${ }^{t-B u}$ PNNP ligand in its three protonation states. Moreover, an interesting trend is observed across the series where the $\mu$-mesityl ligand appears to change from a symmetric $3 \mathrm{c}-2 \mathrm{e}$ binding mode to a situation approaching the $2 \mathrm{c}-2 \mathrm{e}$ bound aryl ligands typically observed in arylcuprates (Scheme 1). A computational investigation substantiates the trends that are observed in the solid-state structures and provides insights into experimentally observed reactivity and varying orientations of the $\mu$-mesityl ligand.

\section{SYNTHESIS AND SPECTROSCOPIC CHARACTERIZATION}

The expanded pincer ligand ${ }^{t-B u}$ PNNP was prepared with a slight modification to the previously reported procedure (see the Supporting Information) in $42 \%$ total yield. Reacting ${ }^{t}$-Bu PNNP with 2.1 equiv of mesitylcopper in THF resulted in clean formation of mesitylene and complex 1 (Scheme 3), which was isolated as a red solid in $95 \%$ yield. The ${ }^{31} \mathrm{P}$ NMR spectrum of 1 in $\mathrm{C}_{6} \mathrm{D}_{6}$ at $298 \mathrm{~K}$ (Figure S5) features two broad resonances at 23.5 and $10.3 \mathrm{ppm}$, showing two magnetically different phosphorus atoms. The loss of the $C_{2 v}$ symmetry of the ligand was also evident from the number of resonances in the ${ }^{1} \mathrm{H}$ and ${ }^{13} \mathrm{C}$ NMR spectra (Figures S3 and S4), which indicate an unsymmetrically substituted naphthyridine. Two doublets at $\delta 4.34 \mathrm{ppm}\left({ }^{2} J_{\mathrm{H}, \mathrm{P}}=2.6 \mathrm{~Hz}\right)$ and $\delta 2.61 \mathrm{ppm}\left({ }^{2} J_{\mathrm{H}, \mathrm{P}}\right.$ $=7.0 \mathrm{~Hz}$ ) with a relative ratio of $1: 2$, which we assign to the methine and methylene linker, further support a partially dearomatized ${ }^{t-\mathrm{Bu}} \mathbf{P N N P} *$ ligand. Additionally, the relative integration of three singlets at $\delta 6.96,2.86$, and $2.30 \mathrm{ppm}$ in a ratio of $2: 6: 3$, respectively, indicates a single symmetrically bound mesityl ligand with magnetically equivalent $o-\mathrm{CH}_{3}$ and $\mathrm{C}-\mathrm{H}$ protons on the NMR time scale.

Treatment of complex 1 with $\left[\mathrm{Et}_{3} \mathrm{NH}\right] \mathrm{Cl}$ results in

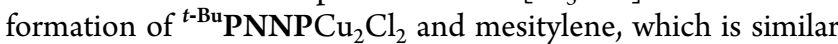
to the reactivity of the previously reported ${ }^{t-\mathrm{Bu}} \mathrm{PNNP} * \mathrm{Cu}_{2} \mathrm{O}-t$ $\mathrm{Bu}$ complex. ' Surprisingly, treatment of 1 with 1 equiv of Brookhart's acid $\left(\left[\mathrm{H}\left(\mathrm{OEt}_{2}\right)_{2}\right] \mathrm{BArF}_{24}\right)^{12}$ at room temperature results in selective protonation on the ${ }^{t-\mathrm{Bu}} \mathrm{PNNP} *$ ligand to give 2, which was isolated as a purple solid in $97 \%$ yield (Scheme 3). The ${ }^{31} \mathrm{P}$ NMR spectrum of 2 in THF- $d_{8}$ at $298 \mathrm{~K}$ (Figure S13) shows a single resonance at $27.7 \mathrm{ppm}$, suggesting magnetically equivalent phosphorus atoms. The ${ }^{1} \mathrm{H}$ and ${ }^{13} \mathrm{C}$ spectra (Figures S9 and S10) show loss of the vinylic resonance observed in 1 , and the expected number of resonances for a $C_{2 v}$-symmetric species is observed.

A related dicopper(I) mesityl anion featuring a fully dearomatized naphthyridine backbone can be prepared by reacting 1 with 1 equiv of benzylpotassium $(\mathrm{KBn})$ and 1 equiv of 18-crown-6 at ambient temperature (Scheme 3). Complex 3

Scheme 3. Synthesis of the Dicopper Mesityl Complexes 1-3

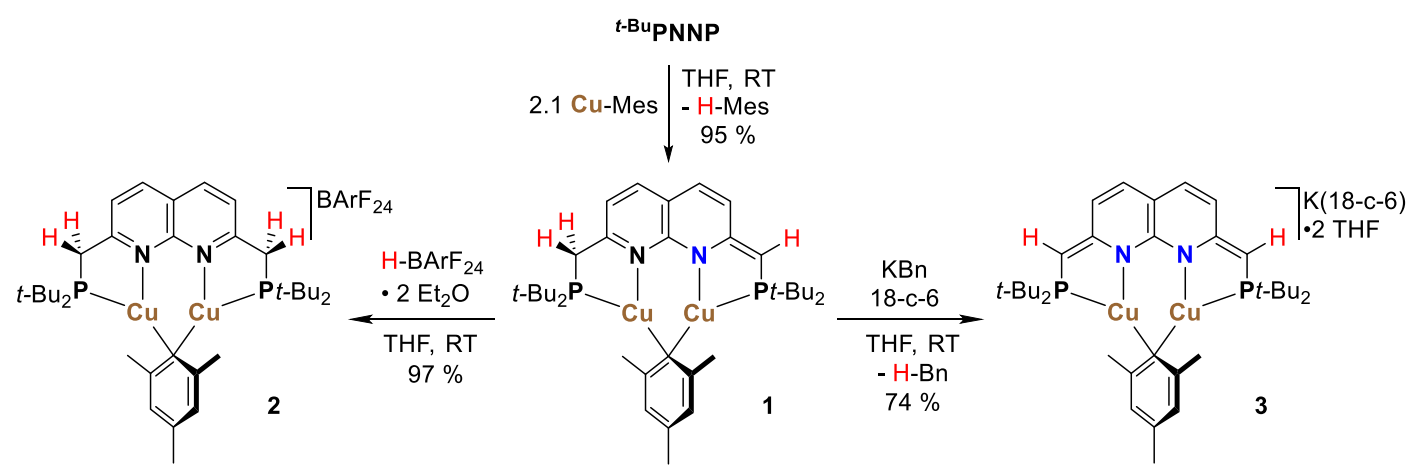



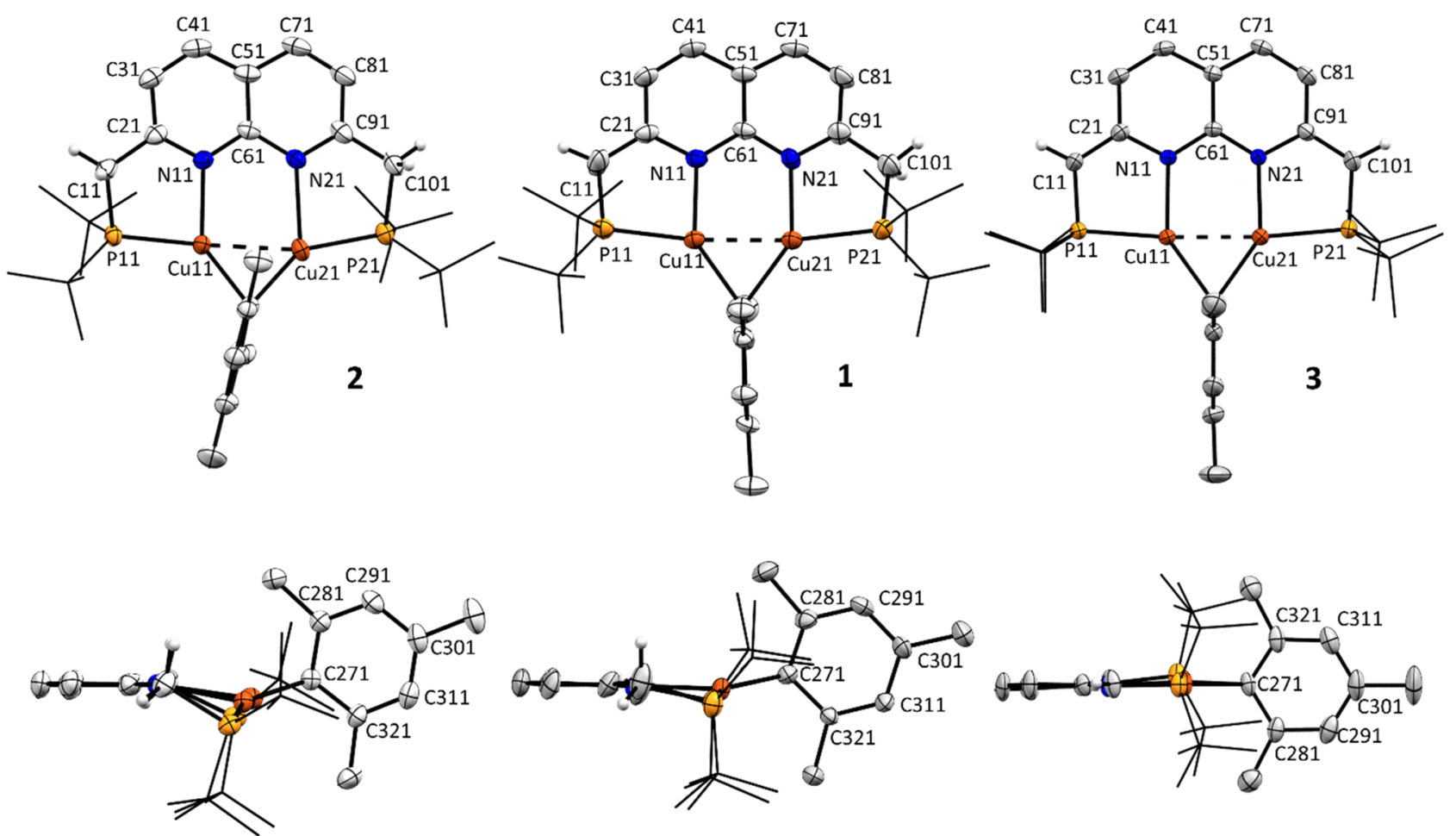

Figure 1. View of the crystal structures perpendicular (top) and parallel (bottom) to the naphthyridine plane, showing the bending and the tilting of the mesityl ligand, respectively. Most hydrogen atoms, counterions, disorder in the $t$-Bu groups, and cocrystallizing molecules are omitted for clarity. The $t$-Bu groups on the phosphorus atoms are depicted in wireframe for clarity, and the displacement ellipsoids are set at the $50 \%$ probability level.

was obtained as a thermally stable orange solid in $74 \%$ yield and readily reacts with traces of proton sources to re-form 1 . The ${ }^{31} \mathrm{P}$ NMR spectrum of 3 in THF- $d_{8}$ at $298 \mathrm{~K}$ (Figure S19) features a single resonance at $\delta 10.1 \mathrm{ppm}$, indicating magnetically equivalent phosphorus atoms. Moreover, the ${ }^{1} \mathrm{H}$ and ${ }^{13} \mathrm{C}$ NMR spectra (Figures S17 and S18) show the expected number of resonances expected for a $C_{2 v}$-symmetric species. The resonance assigned to the vinylic linker at $\delta 3.20$ ppm $\left({ }^{2} J_{\mathrm{H}, \mathrm{P}}=2.5 \mathrm{~Hz}\right)$ in the ${ }^{1} \mathrm{H}$ NMR spectrum integrates equally $(2 \mathrm{H})$ to the naphthyridine resonances, which are found at 6.11 and $5.52 \mathrm{ppm}$, in agreement with full dearomatization of the naphthyridine core.

\section{STRUCTURAL CHARACTERIZATION}

Single crystals of $\mathbf{1}$ suitable for X-ray diffraction were grown from a saturated hexane solution at $-40{ }^{\circ} \mathrm{C}$. The solid-state structure (Figure 1, middle) shows a nearly symmetrical mesityl ligand bridging two copper centers. Characteristic metric parameters associated with the ${ }^{t-\mathrm{Bu}} \mathrm{PNNP}^{*}$ ligand are observed (see detailed discussion below). Both copper centers show a Y-shaped geometry and are separated by 2.3899 (7) A, which is significantly shorter than the $\mathrm{Cu}-\mathrm{Cu}$ distance in metallic copper $(2.556 \AA) .{ }^{13}$ The short $\mathrm{Cu}-\mathrm{Cu}$ distance is not uncommon for $\mu$-aryl copper complexes due to electrondeficient $3 \mathrm{c}-2 \mathrm{e}$ bonding ${ }^{2-4}$ and is comparable to those for the $\mu$-aryl dicopper(I) complexes bearing a naphthyridine bis(dipyridyl) ligand reported by the Tilley group. ${ }^{10,11}$ The copper-carbon distances $(\mathrm{Cu} 11-\mathrm{C} 271=2.037(5) \AA$ and $\mathrm{Cu} 21-\mathrm{C} 271=2.046(5) \AA$ ) are not significantly different, but a slight bending of the bridging mesityl moiety is observed $\left(\angle \mathrm{Cu} 11-\mathrm{C} 271-\mathrm{C} 301=147.1(3)^{\circ} ; \angle \mathrm{Cu} 21-\mathrm{C} 271-\mathrm{C} 301=\right.$ $\left.141.1(3)^{\circ}\right)$ to align it with $\mathrm{Cu} 11$, which is in the dearomatized binding pocket. Surprisingly, the $\mu$-mesityl ligand is tilted out of the naphthyridine plane, and this is clearly reflected in the $15.0(2)^{\circ}$ angle between the C51-C61 bond and C271-C301 vector (Figure 1, bottom middle). Despite the observed nonsymmetric binding of the $\mu$-mesityl ligand in the solid-state structure, no broadening or separation of the three mesityl resonances was observed in the ${ }^{1} \mathrm{H}$ NMR spectra of 1 recorded in THF- $d_{8}$ between 188 and $298 \mathrm{~K}$ (Figure S23). There are no obvious crystal-packing effects observed in the solid-state structure, suggesting that the bend could originate from electronic preference and that the energetic barrier for fluxional behavior is too low to be observed by NMR.

Crystals of $\mathbf{2}$ suitable for X-ray diffraction were grown from a saturated benzene solution at room temperature. The solidstate structure revealed a structure similar to that observed for 1 but with characteristic metric parameters of the ${ }^{t \text {-Bu PNNP }}$ ligand (see detailed discussion below) in a 1:1 ratio with a $\mathrm{BArF}_{24}$ anion. Both copper centers in 2 still show Y-shaped geometries, but the $\mathrm{Cu}-\mathrm{Cu}$ distance $(2.4521(3) \AA)$ is longer by $0.0622(8) \AA$ in comparison to that observed for complex 1 . The copper-carbon distances $(2.0127(16)$ and 2.0134(16) $\AA$ ) are slightly shorter and the bridging mesityl moiety is significantly more bent than in complex 1 ( $\angle \mathrm{Cu} 11-\mathrm{C} 271-$ $\left.\mathrm{C} 301=130.96(8)^{\circ} ; \angle \mathrm{Cu} 21-\mathrm{C} 271-\mathrm{C} 301=153.79(9)^{\circ}\right)$. In combination with the longer $\mathrm{Cu} 21-\mathrm{N} 21$ distance of 2.2550(14) $\AA$ in comparison to the Cu11-N11 distance of 2.1087(13) $\AA$, the binding situation in 2 resembles an intermediate case $\mathrm{e}^{14}$ between a $3 \mathrm{c}$-2e bound $\mu$-mesityl and a 2c-2e $\sigma$-bound mesityl stabilized by $\pi$ donation to a cationic metal, which is commonly encountered in cuprates. ${ }^{1,2,7}$ Moreover, the $\mathrm{P}-\mathrm{Cu}, \mathrm{C}-\mathrm{Cu}$, and $\mathrm{Cu}-\mathrm{N}$ distances in $\mathbf{2}$ are comparable to those observed in a related mononuclear $\mathrm{Cu}$ 
Table 1. Selected Bond Distances ( $\AA$ ) for Complexes 1-3

\begin{tabular}{|c|c|c|c|}
\hline bond & {$\left[{ }^{t-\mathrm{Bu}} \mathrm{PNNPCu}_{2} \mathrm{Mes}\right] \mathrm{BArF}_{24}(2)$} & ${ }^{t-\mathrm{Bu}} \mathrm{PNNP} * \mathrm{Cu}_{2} \mathrm{Mes}(\mathbf{1})$ & $\mathrm{K}(18-\mathrm{c}-6)\left[{ }^{t-\mathrm{Bu}} \mathrm{PNNP}{ }^{* *} \mathrm{Cu}_{2} \mathrm{Mes}\right](3)$ \\
\hline $\mathrm{Cu} 11-\mathrm{Cu} 21$ & $2.4521(3)$ & $2.3899(7)$ & $2.3870(6)$ \\
\hline $\mathrm{Cu} 11-\mathrm{P} 11$ & $2.2346(5)$ & $2.2620(15)$ & $2.2777(11)$ \\
\hline $\mathrm{Cu} 21-\mathrm{P} 21$ & $2.2353(4)$ & $2.2491(15)$ & $2.2769(11)$ \\
\hline Cu11-N11 & $2.1087(13)$ & $2.061(4)$ & $2.043(3)$ \\
\hline $\mathrm{Cu} 21-\mathrm{N} 21$ & $2.2550(14)$ & $2.075(4)$ & $2.036(3)$ \\
\hline $\mathrm{Cu} 11-\mathrm{C} 271$ & $2.0127(16)$ & $2.037(5)$ & $2.056(4)$ \\
\hline $\mathrm{Cu} 21-\mathrm{C} 271$ & $2.0134(16)$ & $2.046(5)$ & $2.058(3)$ \\
\hline $\mathrm{P} 11-\mathrm{C} 11$ & $1.8508(18)$ & $1.794(6)$ & $1.755(4)$ \\
\hline $\mathrm{P} 21-\mathrm{C} 101$ & $1.8516(19)$ & $1.834(5)$ & $1.757(4)$ \\
\hline $\mathrm{C} 21-\mathrm{N} 11$ & $1.331(2)$ & $1.385(8)$ & $1.385(4)$ \\
\hline $\mathrm{C} 91-\mathrm{N} 21$ & $1.326(2)$ & $1.357(8)$ & $1.385(4)$ \\
\hline $\mathrm{C} 11-\mathrm{C} 21$ & $1.508(2)$ & $1.400(9)$ & $1.391(5)$ \\
\hline $\mathrm{C} 21-\mathrm{C} 31$ & $1.413(2)$ & $1.435(7)$ & $1.434(5)$ \\
\hline C $31-C 41$ & $1.355(3)$ & $1.351(7)$ & $1.360(5)$ \\
\hline $\mathrm{C} 41-\mathrm{C} 51$ & $1.403(3)$ & $1.414(8)$ & $1.414(5)$ \\
\hline C51-C71 & $1.409(3)$ & $1.402(8)$ & $1.402(5)$ \\
\hline $\mathrm{C} 71-\mathrm{C} 81$ & $1.354(3)$ & $1.367(8)$ & $1.357(5)$ \\
\hline C81-C91 & $1.416(3)$ & $1.404(8)$ & $1.437(5)$ \\
\hline C91-C101 & $1.505(3)$ & $1.461(9)$ & $1.386(5)$ \\
\hline $\mathrm{C} 271-\mathrm{C} 281$ & $1.415(2)$ & $1.414(6)$ & $1.416(5)$ \\
\hline C271-C321 & $1.417(2)$ & $1.424(5)$ & $1.416(5)$ \\
\hline
\end{tabular}

complex featuring a 2c-2e $\sigma$-bound phenyl ligand and a bidentate $\mathrm{P}^{t-\mathrm{Bu}} \mathrm{N}$ ligand $(\mathrm{N}-\mathrm{Cu} 2.305(6) \AA ; \mathrm{Cu}-\mathrm{P} 2.199(2)$ $\AA$; $\mathrm{Cu}-\mathrm{C}=1.948(8) \AA) .{ }^{15}$ The $26.45(8)^{\circ}$ angle between the C51-C61 bond and C271-C301 vector shows that the $\mu$ mesityl ligand is significantly tilted further out of the naphthyridine plane (Figure 1, bottom left) than was observed in the solid-state structure of $\mathbf{1}$. Notably, both $\mathrm{Cu}$ atoms in complex $\mathbf{2}$ are not within the naphthyridine plane (Figure S32), likely enabled by the flexible methylene linkers in the ${ }^{t}$-Bu PNNP ligand. Despite the more distorted solid-state structure in comparison to $\mathbf{1}$, no fluxional bending or tilting of the mesityl ligand in $\mathbf{2}$ could be observed by NMR spectroscopy between 183 and $298 \mathrm{~K}$ in THF- $d_{8}$ (Figure S24). This suggests that, despite the larger bend and tilt observed in the solid-state structure, the energetic barrier is too low to be observed by NMR within this temperature range.

Crystals of 3 suitable for X-ray diffraction were grown from a THF/HMDSO mixture at $-40{ }^{\circ} \mathrm{C}$. The solid-state structure of 3 (Figure 1, right) revealed a structure similar to those observed for $\mathbf{1}$ and $\mathbf{2}$ but with metric parameters characteristic for the ${ }^{t-\mathrm{Bu}} \mathrm{PNNP}^{* *}$ ligand (see detailed discussion below) in a 1:1 stoichiometry with 18-crown-6 sequestered potassium cations. There are two independent cations in the asymmetric unit which are both located on inversion centers, while the anion is on a general position without symmetry. The copper centers are separated by $2.3870(6) \AA$ and are held within the naphthyridine plane (Figure S32). The copper-carbon distances $(\mathrm{Cu} 11-\mathrm{C} 271=2.058(3) \AA$; $\mathrm{Cu} 21-\mathrm{C} 271$ 2.058(4) $\AA)$ are slightly longer than in complex 1, as expected for an anionic complex. The most notable feature is the highly symmetric binding of the $\mu$-mesityl ligand ( $\angle \mathrm{Cu} 11-\mathrm{C} 271-$ $\left.\mathrm{C} 301=145.1(2)^{\circ} ; \angle \mathrm{Cu} 21-\mathrm{C} 271-\mathrm{C} 301=144.0(2)^{\circ}\right)$ in comparison to the bent orientations observed in complexes 1 and 2. This is also reflected in the small angle of $2.24(19)^{\circ}$ between the C51-C61 bond and C271-C301 vector that shows the tilting of the $\mu$-mesityl ligand with respect to the naphthyridine plane (Figure 1, bottom right). The central sixmembered chelate ring in complex 3 is nearly flat, but this ring shows increasing ring puckering in $\mathbf{1}$ and $\mathbf{2}$ (Figure S32). This is reflected in the angles between the $\mathrm{Cu} 11-\mathrm{C} 271-\mathrm{Cu} 21$ plane and the plane that intersects Cu11-N11-C61-N21$\mathrm{Cu} 21$ : for $2,26.63(7)^{\circ}$; for $1,14.29(19)^{\circ}$; for $3,2.73(17)^{\circ}$.

\section{TRENDS BETWEEN THE DIFFERENT LIGAND PROTONATION STATES}

With the structurally similar complexes 1-3 in hand that solely differ in the counterion and protonation state of the expanded pincer ligand, we were interested to discover distinct metric parameters (Table 1) and spectroscopic features that could aid in the assignment of ligand protonation states. The $\mathrm{Cu}-\mathrm{Cu}$ distance in $\mathbf{2}$ is significantly longer than those observed in $\mathbf{1}$ and 3. However, a comparison with the previously reported complexes bearing a $\mu$-O-t-Bu or two $\mu$-Cl ligands ${ }^{9}$ shows that each protonation state of the expanded pincer ligand can bind two $\mathrm{Cu}$ centers at varying distances, which appear to be most influenced by the nature of the additional (bridging) ligand. Although an increase in the $\mathrm{Cu}-\mathrm{P}$ distances is observed as we move from 2 to $\mathbf{1}$ to 3 , this trend is not observed in the previously reported complexes. ${ }^{9}$ A trend in shortening of the $\mathrm{N}-\mathrm{Cu}$ distances is observed upon partial and full dearomatization of the ${ }^{t \text {-Bu} P N N P ~ l i g a n d, ~ w h i c h ~ w a s ~ a l s o ~ o b s e r v e d ~ i n ~ t h e ~}$ previously reported complexes. Despite the trend, the nature of the bridging coligand also affects this parameter to an extent that makes it not possible to assign a ligand protonation state on the basis of the $\mathrm{Cu}-\mathrm{N}$ distance.

In the solid-state structure of the previously reported ${ }^{t-B u}$ PNNP* ${ }^{*} u_{2} \mathrm{O}-t-\mathrm{Bu}$ complex, the naphthyridine core features a distinct aromatic and dearomatized ring, the latter of which displayed clear localization of single and double bonds, and this was in agreement with the DFT-optimized geometry. Although a clear localization is also observed in the dearomatized pocket in complex 1, the other ring also shows relatively localized single and double bonds. The bond lengths in the DFT optimized geometry of $\mathbf{1}$ (see below) are more in line with the previously observed distinct aromatic and dearomatized rings. As there are some short contacts involving 
the naphthyridine ring in the solid-state structure of $\mathbf{1}$, it is conceivable that these affect the intra-naphthyridine bond lengths. Regardless, this is a clear indication that one should be cautious in using the bond lengths within the naphthyridine to assign the PNNP ligand protonation state. This is further underlined by the observation that there are clear bond length alternations within the naphthyridine in $\mathbf{2}$ and in the previously reported ${ }^{t-\mathrm{Bu}} \mathrm{PNNPCuCl}_{2}$, ${ }^{9}$ something that is a typical feature of bicyclic aromatics. ${ }^{16}$

Analogous to the lutidine-derived PNP pincer ligands, there are two resonance forms which can be drawn upon deprotonation of the methylene arm of the ${ }^{t-B u}$ PNNP ligand (Scheme 4). ${ }^{17}$ Although the resonance structure featuring an

Scheme 4. Resonance Forms of the Deprotonated Section of the ${ }^{t-B u}$ PNNP* Ligand

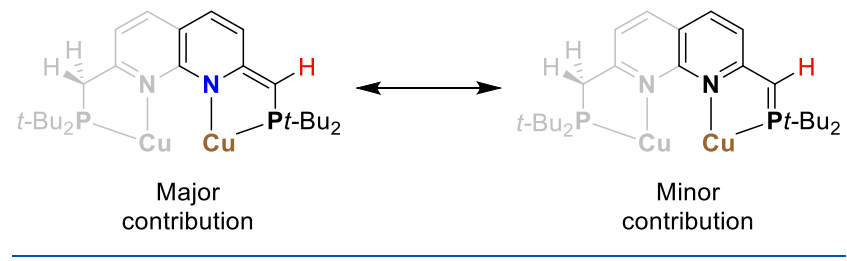

aromatic ring and partial $\mathrm{P}-\mathrm{CH}$ double-bond character similar to what is observed in phosphorus ylides has a minor contribution, it results in a noticeable shortening of the corresponding $\mathrm{CH}-\mathrm{P}$ bond and contributes to the overall ligand rigidity. The only bond lengths that are consistently distinct for the protonation state of the expanded pincer ligand throughout all complexes are the C11-P11/C101-P21 and C11-C21/C91-C101 distances. Upon deprotonation of a methylene arm in the ${ }^{t-\mathrm{Bu}} \mathrm{PNNP}$ ligand a contraction of the corresponding $\mathrm{C} 11-\mathrm{C} 21 / \mathrm{C} 91-\mathrm{C} 101$ bonds from $\sim 1.51$ to $\sim 1.39 \AA$ is observed. Additionally, a contraction of the corresponding $\mathrm{C} 11-\mathrm{P} 11 / \mathrm{C} 101-\mathrm{P} 21$ bond from $\sim 1.84$ to $\sim 1.76 \AA$ can be observed. These changes are most evident

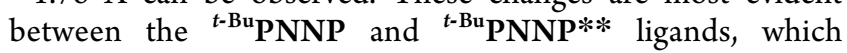

suggests that there is some delocalization of charge throughout the whole naphthyridine in the ${ }^{t-B u}$ PNNP* ligand. Related but less clear trends for the $\mathrm{C} 21-\mathrm{N} 11 / \mathrm{C} 91-\mathrm{N} 21$ bonds can be observed for the different protonation states. As each side of a

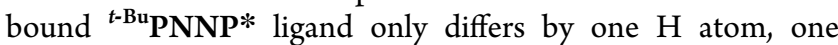
should exercise caution in assigning the dearomatized pocket solely on the basis of intraligand bond lengths, especially when the $\mathrm{H}$ atoms on $\mathrm{C} 11$ and $\mathrm{C} 101$ are not visible in the difference Fourier maps.

These protonation-state-dependent trends are not only limited to bond metrics but are also expressed in NMR spectroscopy. Depending on whether the $\mathrm{P}$ atom is connected to a methylene or a methine linker, a resonance in the ${ }^{31} \mathrm{P}$ NMR spectrum of dicopper(I) complexes can be found around $\delta 25$ or $10 \mathrm{ppm}$, respectively. Similarly, a clear trend is also observed for the chemical shifts of the naphthyridine resonances in the ${ }^{1} \mathrm{H}$ NMR spectra of dicopper(I) complexes: $\delta 8.6-7.3 \mathrm{ppm}$ for a fully protonated backbone, $\delta 7.0-6.0 \mathrm{ppm}$ for the partially dearomatized naphthyridine, and $\delta 6.4-5.4$ ppm for the fully dearomatized naphthyridine. This upfield shift of the resonances is in line with the loss of aromatic character of the naphthyridine upon deprotonation, leading to a more vinylic character of these resonances. Although significant changes are observed in the vibrational spectra of 1-3, we have thus far not been able to identify a distinct feature that we can correlate to the specific protonation state of the expanded pincer ligand.

\section{COMPUTATIONAL INSIGHTS}

In order to gain insight into the difference in electronic structures of 1-3 and how this correlates to the observed varying degrees of bending/tilting of the $\mu$-mesityl, we studied the dicopper(I) fragments in 1-3 computationally using DFT calculations. The geometries obtained from gas-phase geometry optimizations of $\mathbf{1}$, the cation of $\mathbf{2}\left(2^{+}\right)$and the anion of 3 $\left(3^{-}\right)$, using either the BP86 or b3-lyp functional with the def2TZVP basis set and empirical dispersion corrections, were

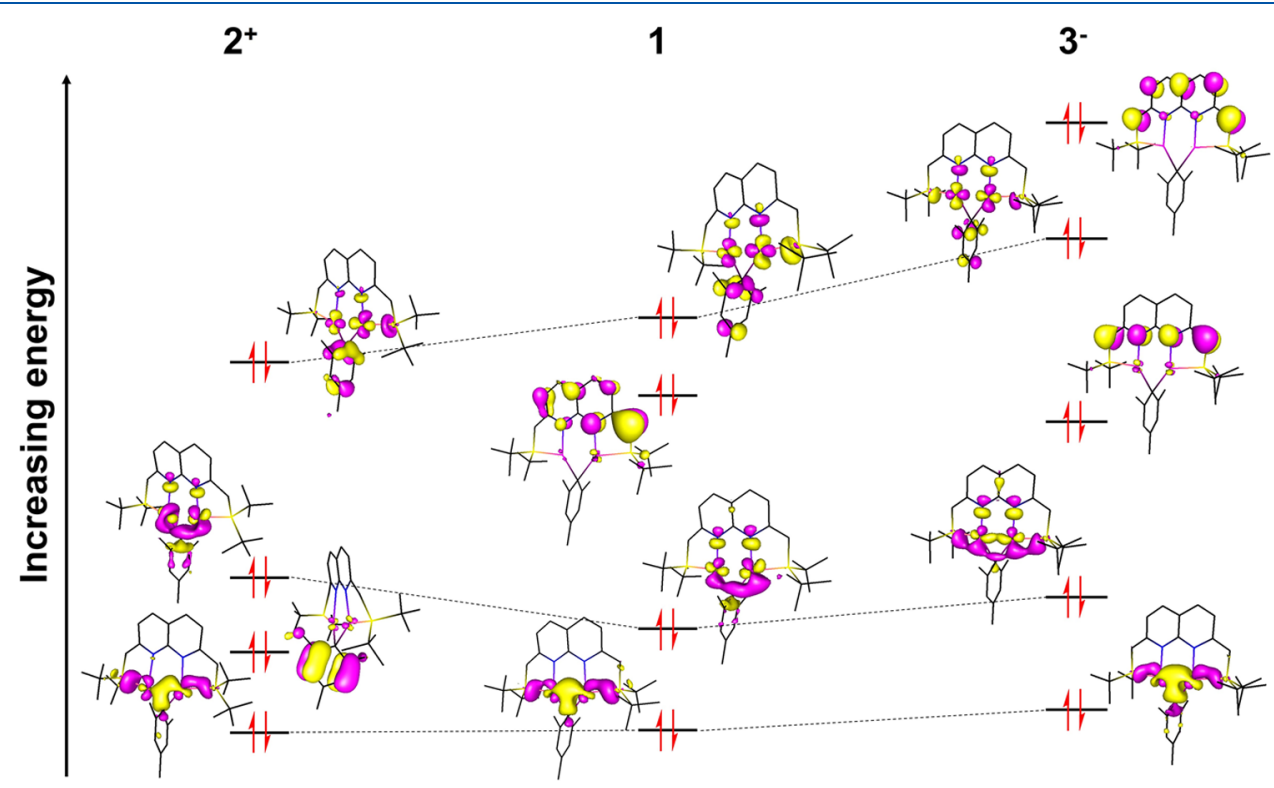

Figure 2. Selection of the calculated (b3-lyp, def2-TZVP) highest occupied MOs (top MO = HOMO) and corresponding Kohn-Sham orbitals of $\mathbf{2}^{+}$(left), 1 (middle), and $\mathbf{3}^{-}$(right). The dashed lines indicate similar MOs between the three compounds. See Figure S29 for a larger selection of the calculated MOs. 
overall consistent with those observed in the experimental solid-state structures (Figures S25-S27). A relaxed surface scan to simulate the flipping of the $\mu$-mesityl from one side of the naphthyridine plane to the other (Figure S28) suggests that the barrier for this process is very low $\left(<1 \mathrm{kcal} \mathrm{mol}^{-1}\right)$ for the cation bearing the flexible ${ }^{t-B u}$ PNNP ligand. This is in agreement with the low-temperature NMR spectra that showed no significant broadening or decoalescence of the resonances, suggesting a low barrier process for reorientation of the $\mu$-mesityl ligand. Since the overall orientations in terms of bending/tilting of the $\mu$-mesityl ligands in complexes $1-3$ are consistent between the experimental and gas-phase optimized geometries, the different binding orientations of the $\mu$-mesityl ligands appear to be inherent due to changes in electronic structure. Analysis of the Kohn-Sham orbitals of the three compounds (Figure 2) revealed various interesting changes in the relative energies and composition of the molecular orbitals (MOs). In agreement with the observed protonation on the ligand in $\mathbf{1}$ and 3 , the highest occupied molecular orbital (HOMO) of $3^{-}$and the HOMO- 1 of $\mathbf{1}$ have large coefficients on the methine carbons in the ligand arms. The HOMO in $2^{+}$is delocalized over the two copper atoms and the $\mu$-mesityl ligand with a significant localization on the ipso carbon. Similar MOs are found in 1 (HOMO) and $3^{-}$ (HOMO-1) but with decreasing localization on the $\mu$-mesityl ligand, and this is most pronounced on the ipso carbon. A similar trend in decreasing localization on the $\mu$-mesityl ligand is observed for a $\mathrm{MO}$ that shows bonding character between the dicopper core and the $\mu$-mesityl ligand $\left(2^{+}, \mathrm{HOMO}-1 ; \mathbf{1}\right.$, HOMO-2; $3^{-}$, HOMO-3). The MO that shows most similarity to a lone pair in a $\mathrm{sp}^{x}$ orbital on the ipso carbon in Scheme 1 is the HOMO-4 in $3^{-}$. This $\mathrm{MO}$ is located symmetrically between the two copper atoms and features an antibonding combination between the mesityl $\sigma$ donor and a bonding set of $\mathrm{d}_{x y}$ orbitals. Similar MOs are found in the HOMO-3 in $\mathbf{1}$ and $2^{+}$with increasing localization toward the copper site that lies closest to the plane of the $\mu$-mesityl ligand.

Because of the difficulty of interpreting the highly delocalized Kohn-Sham orbitals, we performed a natural bonding orbital (NBO) analysis ${ }^{18}$ of $\mathbf{2}^{+}, \mathbf{1}$, and $\mathbf{3}^{-}$. For all three compounds a NBO was found consisting of a lone pair in an $\mathrm{sp}^{x}$ hybrid orbital on the ipso carbon on the $\mu$-mesityl ligand. Proceeding from the cationic to the anionic complex, the occupancy of this NBO increases slightly, indicating a weaker interaction, and the $\mathrm{p}$ character of this NBO decreases $\left(1.59 \mathrm{e}^{-}\right.$ in $\mathrm{sp}^{2.65}$ for $2^{+}$to $1.63 \mathrm{e}^{-}$in $\mathrm{sp}^{2.38}$ for $3^{-}$) proceeding from the cationic to the anionic complex. A similar trend was also observed in the Löwdin analysis of the IAOIBO ${ }^{19}$ localized orbitals (see the Supporting Information). We used the NBO second-order perturbative energy analysis to examine the extent of interaction of "filled" donor NBOs with "empty" acceptor NBOs in the dicopper core and the $\mu$-mesityl ligand. Graphical representations of the type of interaction, the corresponding delocalization energy (numbers in black), and the associated calculated filled (solid) and empty (translucent) NBOs in 1-3 are depicted in Figure 3. In all three compounds it is clear that the donation of the lone pair on the ipso carbon into the empty 4 s orbital on the copper sites (A) is the main contributor to the electron-deficient $3 c-2 e$ bonding. The delocalization energy of this donor-acceptor interaction decreases in strength from $107.3 \mathrm{kcal} \mathrm{mol}^{-1}$ in $2^{+}$to 95.9 $\mathrm{kcal} \mathrm{mol}^{-1}$ in $3^{-}$, which is in agreement with the more electron deficient nature of $\mathbf{2}^{+}$. Similar observations that are in line with

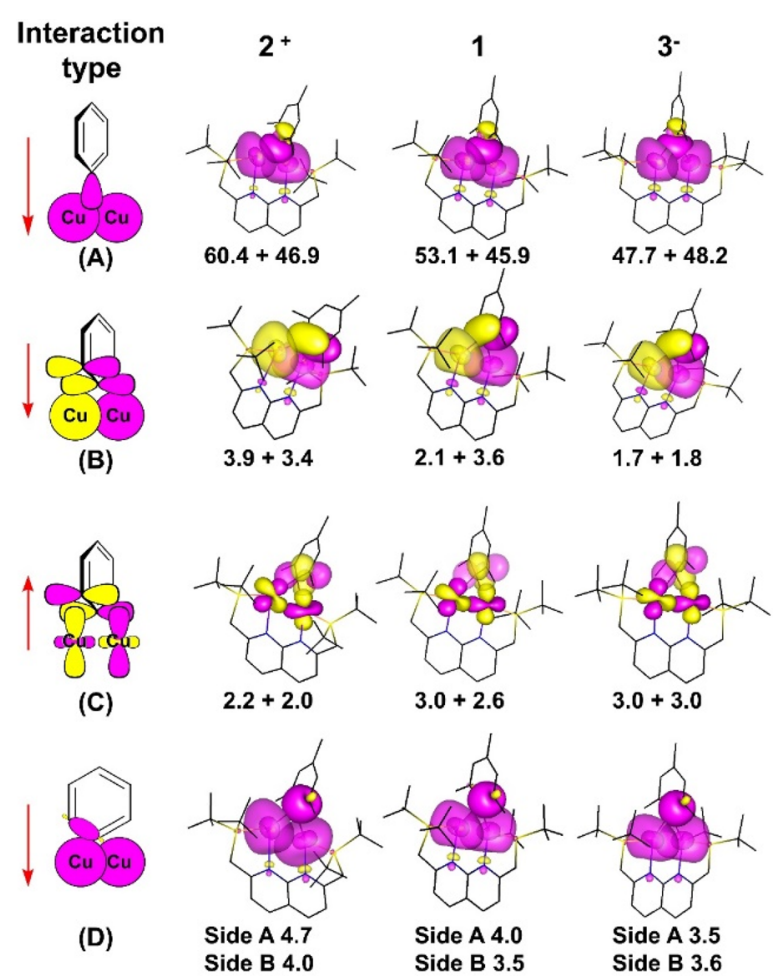

Figure 3. (left) Graphical representations of the four prevailing donor-acceptor interactions between the $\mu$-mesityl ligand and copper atoms in 1-3 and (right) the corresponding calculated occupied (solid) and unoccupied (transparent) NBOs. For interaction type AC each number in black represents the corresponding delocalization energy to each $\mathrm{Cu}$, whereas for interaction type $\mathbf{D}$ the numbers represent the delocalization energy for the $\mathrm{C}-\mathrm{C}_{\mathrm{ipso}} \sigma$ bonds on each side to both $\mathrm{Cu}$ atoms. The red arrows indicate the direction of donation.

the overall change in electron density on the $\mathrm{Cu}$ centers are made for interaction types $\mathbf{B}$ and $\mathbf{C}$, which only make a minor contribution to the $3 \mathrm{c}-2 \mathrm{e}$ bonding. An additional minor donor-acceptor contribution was found involving donation of both $\mathrm{C}-\mathrm{C}_{\text {ipso }} \sigma$ bonds to the ipso carbon into the empty $4 \mathrm{~s}$ orbitals on $\mathrm{Cu}(\mathbf{D})$, and the trends in delocalization energies are also in line with the expected changes in electron density on the $\mathrm{Cu}$ sites. An interesting distinction between the individual $\mathrm{Cu}$ sites within $\mathbf{1 - 3}$ is found for the interaction type A. In the case of $3^{-}$the delocalization energies of the $\mathrm{C}_{\text {ipso }}$ lone pair into the individual unoccupied $\mathrm{Cu} 4 \mathrm{~s}$ orbitals are nearly equal, in agreement with symmetric $3 \mathrm{c}-2 \mathrm{e}$ bonding. For a pure $2 \mathrm{c}$-2e $\sigma$-bound aryl this interaction type would still be the main contributor but would only involve a single $\mathrm{Cu}$ site. In agreement with a bonding situation in $2^{+}$that leans slightly toward this scenario, there is a stronger interaction (by $\sim 13$ $\mathrm{kcal} \mathrm{mol}^{-1}$ ) to $\mathrm{Cul}$, which is the copper site with the significantly longer $\mathrm{Cu}-\mathrm{N}$ distance.

\section{DISCUSSION OF THE $\mu$-MESITYL BONDING}

The bonding of the $\mu$-mesityl ligand to the dicopper(I) cores appears to change from a symmetric $3 \mathrm{c}-2 \mathrm{e}$ electron bonding mode in 3 toward a situation that approaches a $2 \mathrm{c}-2 \mathrm{e}$ bound with a stabilizing cation $\pi$-type interaction (Scheme 1 ) in 2 . We reason that these changes are due to a combination of varying rigidity of the expanded pincer ligand and inclination to enable a cation-stabilized linear $2 \mathrm{c}$-2e $\sigma$-bound aryl ligand. 
Related deviations from the symmetrical $3 c-2 e$ bonding in $\mathrm{Cu}_{n} \mathrm{Mes}_{n}$ have been observed in the presence of substoichiometric (with respect to $\mathrm{Cu}$ ) amounts of coordinating ligands such as dimethyl sulfide ${ }^{20}$ or tetrahydrothiophene. ${ }^{3 a}$ It is worth mentioning that no significant bending of a $\mu$-phenyl ligand was observed in a related cationic naphthyridine bis(dipyridyl) dicopper(I) complex reported by the group of Tilley. ${ }^{10}$ It appears that the more flexible ${ }^{t-B u}$ PNNP ligand in $\mathbf{2}$ enables the required bending and tilting of the $\mu$-mesityl ligand to accommodate a coordination geometry around $\mathrm{Cu} 1$ that approaches a linear $\mathrm{P}-\mathrm{Cu}$-mesityl motif featuring a $\pi$-type interaction with a PN-stabilized cationic Cu2. Similar situations have been observed for arylcopper complexes where the $\mu$-aryl features an additional donor atom. ${ }^{21} \mathrm{~A}$ similar but less pronounced effect is seen for $\mathbf{1}$, in which ${ }^{t}$-Bu PNNP* features one flexible methylene ligand arm, and the calculated delocalization energy of the $C_{\text {ipso }}$ lone pair is stronger to the unoccupied $4 \mathrm{~s}$ orbital on $\mathrm{Cu} 1$ by $\sim 7 \mathrm{kcal} \mathrm{mol}^{-1}$ (Figure 3). Interestingly, $\mathrm{Cu} 1$ in $\mathbf{1}$ is bound within the dearomatized pocket of the ${ }^{t \text {-Bu }}$ PNNP* ligand, implying local cuprate-like character. Together with the observed stronger $\mathrm{C}-\mathrm{C}_{\text {ipso }} \pi$ donation toward $\mathrm{Cu} 2$ in comparison to $\mathrm{Cu} 1$ in 2 , it appears that the bonding situation of the $\mu$-mesityl ligand in 2 leans slightly toward the 2c-2e $\sigma$-bound aryl stabilized by $\pi$ donation to a cationic metal, as commonly encountered in arylcuprate structures. Along these lines we reason that the lack of tilting and bending in 3 is because the ${ }^{t-B u}$ PNNP** ligand provides a rigid and symmetric coordination environment for the dicopper(I) core. Additionally, as both $\mathrm{Cu}$ sites gain partial cuprate character upon interaction with the $\mu$-mesityl ligand in 3 , there is no beneficial bent/tilted geometry wherein a single cuprate-like $\mathrm{Cu}$ site would gain stabilization of a formal copper cation.

\section{CONCLUSION}

The results herein demonstrate that the ${ }^{t-B u}$ PNNP ligand can accommodate discrete forms of $\mathrm{Cu}_{2} \mathrm{Mes}$ and that the nature of the $3 \mathrm{c}-2 \mathrm{e}$ bond can be tuned as a function of the expanded pincer's protonation state. Proceeding from the anionic to the cationic complex, the changing bonding situation expresses itself by an increased bending and tilting of the $\mu$-mesityl, which was observed in both the solid-state structures and DFT-optimized geometries. We propose that these changes originate from a combination of decreasing ligand rigidity paired with the increasing tendency to form a cation-stabilized linear 2c-2e $\sigma$-bound aryl ligand, as is often observed for cuprates and bidentate ligand stabilized copper aryl complexes. Moreover, we have been able to identify key metrical and spectroscopic parameters that can aid in the protonation state assignment of the ${ }^{t-B u}$ PNNP ligand in bimetallic complexes derived from it.

This work provides new insights on how to tune the electronic structure of well-defined forms of dinuclear organocopper complexes. Given the large role that organocopper reagents play in synthetic chemistry, we expect that our findings could be of help in the development of new reagent types featuring unprecedented reactivity.

\section{ASSOCIATED CONTENT}

\section{SI Supporting Information}

The Supporting Information is available free of charge at https://pubs.acs.org/doi/10.1021/acs.organomet.9b00829.
Experimental procedures, NMR spectra, graphical procedure, and computational and crystallographic computational details (PDF)

\section{Accession Codes}

CCDC 1963847-1963849 contain the supplementary crystallographic data for this paper. These data can be obtained free of charge via www.ccdc.cam.ac.uk/data_request/cif, or by emailing data_request@ccdc.cam.ac.uk, or by contacting The Cambridge Crystallographic Data Centre, 12 Union Road, Cambridge CB2 1EZ, UK; fax: +44 1223336033.

\section{AUTHOR INFORMATION}

\section{Corresponding Author}

Daniël L. J. Broere - Organic Chemistry and Catalysis, Debye Institute for Nanomaterials Science Faculty of Science, Utrecht University, 3584 CG Utrecht, The Netherlands; 이이.org/ 0000-0002-6641-4092; Email: d.l.j.broere@uu.nl

\section{Authors}

Errikos Kounalis - Organic Chemistry and Catalysis, Debye Institute for Nanomaterials Science Faculty of Science, Utrecht University, 3584 CG Utrecht, The Netherlands

Martin Lutz - Crystal and Structural Chemistry, Bijvoet Center for Biomolecular Research Faculty of Science, Utrecht University, $3584 \mathrm{CH}$ Utrecht, The Netherlands

Complete contact information is available at:

https://pubs.acs.org/10.1021/acs.organomet.9b00829

\section{Notes}

The authors declare no competing financial interest.

\section{ACKNOWLEDGMENTS}

This work was supported by The Netherlands Organization for Scientific Research (START-UP grant 740.018.019 to D.L.J.B.) and the European Union's Horizon 2020 research and innovation program (agreement 840836, MSCA-IF to D.L.J.B., BiMetaCat). Access to supercomputer facilities was sponsored by NWO Exacte en Natuurwetenschappen (Physical Sciences). The X-ray diffractometer was financed by the NWO. Gerard van Koten, Bert Klein-Gebbink, and MarcEtienne Moret are acknowledged for valuable discussions and suggestions. NMR data files and ORCA input and output files can be obtained free of charge from DOI: 10.4121/ uuid:7e6e17ba-37fc-4d68-84a6-cc3fa71041a1.

\section{REFERENCES}

(1) (a) Krause, N. Modern Organocopper Chemistry; Wiley-VCH: Weinheim, Germany, 2002. (b) Surry, D. S.; Spring, D. R. The oxidation of organocuprates-an offbeat strategy for synthesis. Chem. Soc. Rev. 2006, 35, 218-225. (c) Breit, B.; Schmidt, Y. Directed Reactions of Organocopper Reagents. Chem. Rev. 2008, 108, 29282951.

(2) (a) van Koten, G. A view of organocopper compounds and cuprates. J. Organomet. Chem. 1990, 400, 283-301. (b) van Koten, G. Organocopper Compounds: From Elusive to Isolable Species, from Early Supramolecular Chemistry with $\mathrm{RCu}^{\mathrm{I}}$ Building Blocks to Mononuclear $\mathrm{R}_{2-\mathrm{n}} \mathrm{Cu}^{\mathrm{II}}$ and $\mathrm{R}_{3-\mathrm{m}} \mathrm{Cu}^{\mathrm{III}}$ Compounds. A Personal View. Organometallics 2012, 31, 7634-7646.

(3) (a) Gambarotta, S.; Floriani, C.; Chiesi-Villa, A.; Guastini, C. Ring Contraction in an Arylcopper(1) Compound promoted by a Sulphur Donor Ligand: Penta[mesitylcopper(I)] forms a Tetra[mesitylcopper(I)] Compound. J. Chem. Soc., Chem. Commun. 1983, 1156-1158. (b) Eriksson, H.; Håkansson, M.; Jagner, S. 
Pentamethylphenylcopper(I): a square-planar tetranuclear cluster. Inorg. Chim. Acta 2006, 359, 2519-2524.

(4) Eriksson, H.; Håkansson, M. Mesitylcopper: Tetrameric and Pentameric. Organometallics 1997, 16, 4243-4244.

(5) Stollenz, M.; Meyer, F. Mesitylcopper - A Powerful Tool in Synthetic Chemistry. Organometallics 2012, 31, 7708-7727.

(6) Belanzoni, P.; Rosi, M.; Sgamelloti, A.; Baerends, E. J.; Gloriani, C. On the electronic structure and bonding of the polynuclear aryl derivatives of the group IB metals $\mathrm{Cu}_{5}\left(\mathrm{C}_{6} \mathrm{H}_{5}\right)_{5}, \mathrm{Ag}_{4}\left(\mathrm{C}_{6} \mathrm{H}_{5}\right)_{4}$ and $\mathrm{Au}_{5}\left(\mathrm{C}_{6} \mathrm{H} 5\right)_{5}$ by density functional theory. Chem. Phys. Lett. 1996, 257, $41-48$.

(7) For example: (a) Lorenzen, N. P.; Weiss, E. Synthesis and Structure of a Dimeric Lithium Diphenylcuprate: $\left[\left\{\mathrm{Li}(\mathrm{OEt})_{2}\right\}-\right.$ $\left.\left(\mathrm{CuPh}_{2}\right)\right]_{2}$. Angew. Chem., Int. Ed. Engl. 1990, 29, 300-302. (b) Khan, S. I.; Edwards, P. G.; Yuan, H. S. H.; Bau, R. Structures of the copper-containing $\mathrm{Cu}_{4} \mathrm{MgPh}_{6}$ and $\left[\mathrm{Cu}_{4} \mathrm{LiPh}_{6}\right]^{-}$clusters: first example of a magnesium-containing transition-metal cluster compound. J. Am. Chem. Soc. 1985, 107, 1682-1684.

(8) (a) Niemeyer, M. $\sigma$-Carbon versus $\pi$-Arene Interactions in the Solid-State Structures of Trimeric and Dimeric Copper Aryls (CuAr) $\left(n=3, \mathrm{Ar}=2,6-\mathrm{Ph}_{2} \mathrm{C}_{6} \mathrm{H}_{3} ; n=2, \mathrm{Ar}=2,6-\mathrm{Mes}_{2} \mathrm{C}_{6} \mathrm{H}_{3}\right)$. Organometallics 1998, 17, 4649-4656. (b) He, X.; Olmstead, M. M.; Power, P. P. Synthesis of $\left[\mathrm{Me}_{2} \mathrm{SCu}\left(\mathrm{C}_{6} \mathrm{H}_{2}-2,4,6\right.\right.$-tert- $\left.\left.\mathrm{Bu}_{3}\right)\right]$ and $\left[\left(\mathrm{Me}_{2} \mathrm{~S}\right)_{2} \mathrm{Cu}(\mu\right.$ $\left.\left.\mathrm{C}_{6} \mathrm{H}_{2}-2,4,6-\mathrm{Ph}_{3}\right) \mathrm{Cu}\left(\mathrm{C}_{6} \mathrm{H}_{2}-2,4,6-\mathrm{Ph}_{3}\right)\right]$ : mononuclear and dinuclear organocopper(I) species of formula [CuR^solvate]1 or 2. J. Am. Chem. Soc. 1992, 114, 9668-9670. (c) Rungthanaphatsophon, P.; Barnes, C. L.; Walensky, J. R. Walensky Copper(I) clusters with bulky dithiocarboxylate, thiolate, and selenolate ligands. Dalton Trans. 2016, $45,14265-14276$.

(9) Kounalis, E.; Lutz, M.; Broere, D. L. J. Cooperative $\mathrm{H}_{2}$ Activation on Dicopper(I) Facilitated by Reversible Dearomatization of an "Expanded PNNP Pincer" Ligand. Chem. - Eur. J. 2019, 25, 13280-13284.

(10) Ziegler, M. S.; Levine, D. S.; Lakshmi, K. V.; Tilley, T. D. Aryl Group Transfer from Tetraarylborato Anions to an Electrophilic Dicopper(I) Center and Mixed-Valence $\mu$-Aryl Dicopper(I,II) Complexes. J. Am. Chem. Soc. 2016, 138, 6484-6491.

(11) Ziegler, M. S.; Torquato, N. A.; Levine; Nicolay, D. S. A.; Celik, H.; Tilley, T. D. Dicopper Alkyl Complexes: Synthesis, Structure, and Unexpected Persistence. Organometallics 2018, 37, 2807-2823.

(12) The greatest of acids, probably, maybe definitely: Brookhart, M.; Grant, B.; Volpe, A. F. $\left[\left(3,5-\left(\mathrm{CF}_{3}\right)_{2} \mathrm{C}_{6} \mathrm{H}_{3}\right)_{4} \mathrm{~B}\right]^{-}\left[\mathrm{H}\left(\mathrm{OEt}_{2}\right)_{2}\right]^{+}$: A convenient reagent for generation and stabilization of cationic, highly electrophilic organometallic complexes". Organometallics 1992, 11, 3920-3922.

(13) Kittel, C. Introduction to Solid-State Physics, 4th ed.; Wiley: New York, 1971.

(14) For a reported intermediate bonding situation see: Nobel, D.; van Koten, G.; Spek, A. L. 2,4,6-Triisopropylphenylcopper, a New Tetranuclear Organocopper Aggregate with Unsymmetrically Bridging $\sigma-\pi$ Bonded Aryl Ligands. Angew. Chem., Int. Ed. Engl. 1989, 28, 208-210.

(15) Gurung, S. K.; Thapa, S.; Kafle, A.; Dickie, D. A.; Giri, R. Copper-Catalyzed Suzuki-Miyaura Coupling of Arylboronate Esters: Transmetalation with (PN)CuF and Identification of Intermediates. Org. Lett. 2014, 16, 1264-1267.

(16) Cruickshank, D. W. J.; Sparks, R. A. Experimental and Theoretical Determinations of Bond Lengths in Naphthalene, Anthracene and Other Hydrocarbons. Proc. R. Soc. London A 1960, $258,270-285$.

(17) Zhang, J.; Leitus, G.; Ben-David, Y.; Milstein, D. Efficient Homogeneous Catalytic Hydrogenation of Esters to Alcohols. Angew. Chem., Int. Ed. 2006, 45 (7), 1113-1115.

(18) Weinhold, F.; Landis, C. R. Valency and Bonding: A Natural Bond Orbital Donor-Acceptor Perspective; Cambridge University Press: 2005.

(19) Knizia, G. Intrinsic Atomic Orbitals: An Unbiased Bridge between Quantum Theory and Chemical Concepts. J. Chem. Theory Comput. 2013, 9, 4834-4843.
(20) Lenders, B.; Grove, D. M.; Smeets, W. J. J.; van der Sluis, P.; Spek, A. L.; van Koten, G. Use of dimethyl sulfide in organocopper chemistry: X-ray crystal structures of cyclo-tetrakis $(\mu-2$ methylphenyl)bis(dimethyl sulfide)tetracopper(I) and of the polymeric copper bromide adduct bromo(dimethyl sulfide)copper(I). Organometallics 1991, 10, 786-791.

(21) van Koten, G.; Jastrzebski, J. T. B. H. Polynuclear Aryl-Copper Species and Neutral Aryl-Cuprates with a Chiral-CH(Me) $\mathrm{NMe}_{2}$ Ortho Substituent. Tetrahedron 1989, 45, 569-578. 